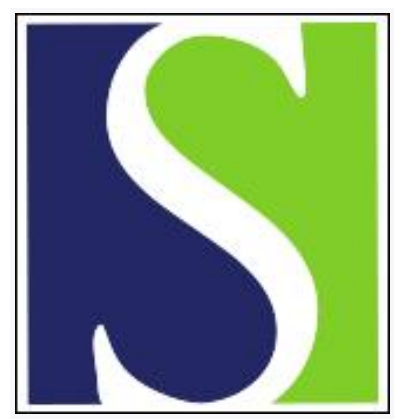

Scand J Work Environ Health 2003;29(5):396-405

https://doi.org/10.5271/sjweh.746

Issue date: Oct 2003

Methodological issues in evaluating workplace interventions to reduce work-related musculoskeletal disorders through mechanical exposure reduction

by Cole DC, Wells RP, Frazer MB, Kerr MS, Neumann WP, Laing AC; Ergonomic Intervention Evaluation Research Group

Affiliation: Institute for Work \& Health, 481 University Avenue, Suite 800, Toronto, ON Canada, M5g 2E9. dcole@iwh.on.ca

Refers to the following texts of the Journal: $2000 ; 26(1): 7-19$ 2002;28(1):18-24 1999;25(6):589-596 1999;25 suppl 4:54-60 $2001 ; 27(6): 381-387$

Key terms: arm pain; back pain; cumulative trauma disorders; discussion paper; ergonomics; evaluation; human factor; mechanical exposure reduction; methodological issue; occupational injury; repetitive strain injury; work-related musculoskeletal disorder; workplace intervention

This article in PubMed: www.ncbi.nlm.nih.gov/pubmed/14584520 


\title{
Methodological issues in evaluating workplace interventions to reduce work-related musculoskeletal disorders through mechanical exposure reduction
}

\author{
by Donald C Cole, MD, ${ }^{1,2}$ Richard P Wells, PhD, ${ }^{3}$ Mardy B Frazer, PhD, ${ }^{3}$ Mickey S Kerr, PhD, , 4 \\ W Patrick Neumann, LSc, ${ }^{5,6}$ Andrew CLaing, MSc, ${ }^{3}$ the Ergonomic Intervention Evaluation \\ Research Group ${ }^{7}$
}

\begin{abstract}
Cole DC, Wells RP, Frazer MB, Kerr MS, Neumann WP, Laing AC, the Ergonomic Intervention Evaluation Research Group. Methodological issues in evaluating workplace interventions to reduce work-related musculoskeletal disorders through mechanical exposure reduction. Scand J Work Environ Health 2003;29(5):396-405.

Researchers of work-related musculoskeletal disorders are increasingly asked about the evidentiary base for mechanical exposure reductions. Mixed messages can arise from the different disciplinary cultures of evidence, and these mixed messages make different sets of findings incommensurate. Interventions also operate at different levels within workplaces and result in different intensities of mechanical exposure reduction. Heterogeneity in reporting intervention processes and in measuring relevant outcomes makes the synthesis of research reports difficult. As a means of synthesizing the current understanding of measures, this paper describes a set of intervention and observation nodes for which relevant workplace indicators prior to, during, and after mechanical exposure reduction can provide useful information. On the basis of this path of impacts from exposure reduction, an approach to the evaluation of multilevel ergonomic interventions is described that can assist fellow researchers in producing evidence relevant to the challenges faced by workplace parties and policy makers.
\end{abstract}

Key terms arm pain, back pain, ergonomics, human factors, occupational injury, repetitive strain injury, cumulative trauma disorders.

\begin{abstract}
A broad range of physical, psychological, and work organizational factors have been epidemiologically established as plausible risk factors for the development of musculoskeletal disorders (1-3). More specifically, the risk of reporting pain increases when there are high peak compressions and shear forces and high cumulative tissue loading due to rapid rates or prolonged durations of worktasks and awkward, repetitive, or prolonged postures associated with worktasks $(2,4-7,8-10)$. High
\end{abstract}

force, frequent repetition, and awkward posture are components of the construct of high mechanical exposure, conceptualized as the magnitude, time variation pattern, and duration of forces on body tissues $(1,11)$.

A general aim of workplace intervention should be to reduce known mechanical exposures, often through "ergonomic" intervention; yet workplace parties have faced conflicting messages about the likely impact of such intervention from researchers (12). Existing review

1 Institute for Work \& Health, Toronto, Ontario, Canada.

2 Department of Public Health Sciences, University of Toronto, Toronto, Ontario, Canada.

3 Department of Kinesiology, University of Waterloo, Waterloo, Ontario, Canada.

4 School of Nursing, Faculty of Health Sciences, University of Western Ontario, London, Ontario, Canada.

5 National Institute for Working Life - West, Göteborg, Sweden.

6 Department of Design Sciences, Lund University, Lund, Sweden.

7 The Ergonomic Intervention Evaluation Research Group [Members at the time of writing, in addition to the authors, included Theberge N, Norman RW, Reid M, Brawley LR, (Department of Kinesiology, University of Waterloo, Waterloo, Canada); Theberge N, Granzow K, Dixon S (Department of Sociology, University of Waterloo, Waterloo, Canada); Tompa E, Ferrier SE, Swift M, Ibrahim S (Institute for Work \& Health, Toronto, Canada); Tompa E (Department of Economics, McMaster University, Hamilton, Canada); Kerton R (Department of Economics, University of Waterloo, Waterloo, Canada].

Reprint requests to: Dr Donald C Cole, Institute for Work \& Health, 481 University Avenue, Suite 800, Toronto, ON, Canada, M5G 2E9. [E-mail: dcole@iwh.on.ca] 
papers on ergonomic intervention usually note that laboratory research has shown a reduction of forces on tissues or improved surface electromyographic responses as indicators of reductions in mechanical exposure; yet field research has been less conclusive $(13,14)$. The conclusiveness of workplace-based evaluations of ergonomic intervention has been reduced by the lack of attention to research design (15); inadequate reporting of uncontrolled cointervention and limited analytic adjustment for such cointervention (16); poor descriptions of populations, exposures, and interventions (17); and inadequate accounting for the timing or impact of interventions (18). In their review of ergonomic interventions, Westgaard \& Winkel (11) commented on each of these issues at some length.

Underlying such mixed messages on intervention effectiveness are different disciplinary cultures of evidence, intervention corresponding to different organizational levels from jobs to workplace policies, varying intensities of intervention, varying considerably by resources allocated by workplaces, and marked heterogeneity in documentation or indicators of both intervention processes and outcomes of interest by researchers and their workplace partners. In this narrative review and conceptual paper, we delineate cultures of evidence, describe issues associated with levels, set out a path linking nodes with associated indicators, and propose an approach to evaluating multilevel ergonomic intervention.

\section{Qultures of evidence}

Different disciplines and different social groups have different conceptions of evidence that they deem persuasive in guiding policy and practice (Upshur et al, unpublished). Douglas \& Wildavsky (19) have described how different sets of shared values and supporting social institutions, or cultures, highlight certain risks and downplay other risks in a process of ongoing reconstruction of evidence and values. In this section, we highlight some of the key contrasts in evidentiary cultures relevant to the reduction of mechanical exposures at work.

Laboratory versus field or workplace. Scientists working predominantly in laboratories characterize a limited set of mechanical exposures using a vast array of intensive measures under highly controlled conditions. Their work has added considerably to our understanding of the biological mechanisms involved in damage to tissues due to various modes of loading $(20,21)$. Furthermore, laboratory testing of means to reduce mechanical exposures provides the closest approximation to the concept of efficacy in clinical research (ie, answers to the question "Can it work?" For example, testing lift assists can show that they reduce peak low-back loads when used according to specifications in lifting tasks for weights of interest (22). Yet direct application of such methods to workplaces is severely constrained due to the limits placed by the field environment on measurement options, the variety of mechanical exposures that may be operative, and the variability of conditions that fluctuate with production demands. Each of these independently precludes the kind of replication under exactly comparable conditions preferred by laboratory scientists.

Experimental versus observational. Linked to the preceding discussion, is the strong preference for more experimental designs in assessing the effectiveness of interventions, predominantly within the agricultural and clinical evidentiary traditions (23). Randomized control trials are carried out to provide the most conclusive type of evidence, followed by quasi-experimental designs (24). Although more common in safety effectiveness research $(25,26)$, randomized controlled trials with ergonomic intervention and individual randomization have contributed relevant evidence (27), and such trials are now underway at the workplace level (Riihimäki H, personal communication).

However, some researchers in the participatory research and action research traditions eschew the investigator control implicit in experimental designs as contrary to effective organizational intervention and the utilization of research results (28). For example, participatory ergonomic change processes produce a wide variety of changes not under the control of the investigators but, rather, under the control of the workplace parties making up the ergonomic change team (29). Furthermore, cointervention is the norm in workplaces. Workplaces suffer unexpected and often rapid market or business plan changes, workforce and manager turnover, and changes in production rates and processes that directly influence work assignments and exposure intensities in ways unforeseen at the time of both the intervention and evaluation planning (30). Griffiths (31) has delineated the limits of the natural science paradigm for organizational interventions and argued for observational designs with greater clarity in the conceptualization and examination of intervention processes. Reviewers coming from ergonomic and epidemiologic traditions have called for more adaptive quasi-experimental and observational designs $(15,16,25,32)$ to provide evidence of the reduction of hazards to inform broad, population-level public health interventions (33).

Quantitative versus qualitative. Although the dominant evaluation paradigm is quantitative, education and management researchers have used case study approaches for many years to capture the complex sets of relationships that define change in organizations $(34,35)$. Qualitative methods are associated with different views of 
evidence and different ways of establishing rigor (36). Mergler (37) has called for greater use of qualitative approaches in occupational health research, while some organizational scientists argue that "standardized questionnaires, structured interviews, and statistical analyses cannot begin to grasp the complex fabric of organizational change [p 92]" (38). On a more moderate note, Robson et al (26) noted important roles for qualitative methods in effectiveness evaluations, particularly with respect to documentary implementation, the "how" of interventions, and the understanding of the "why" of program effectiveness (or lack thereof).

Eficiency versus effectiveness. In market economies, a "business case" based on cost-benefit or return-on-investment analyses often has greater persuasive value with management in workplaces and policymakers in governments than researchers' evidence of effectiveness (39). Substantially reduced workers' compensation costs in association with relatively small investments in workplace ergonomic programs have been a key message in reports by government agencies in the United States (3, 40). In such situations, "administrative" effect sizes (the cost savings resulting from an intervention deemed important by managers) may be far larger than biomechanical effect sizes (changes deemed important by ergonomists) or clinical ones (changes deemed important by clinicians). This circumstance may be especially true for ergonomic contributions at the design phase rather than those resulting in retrofits (41), although an estimation of avoided health risks is associated with uncertainties.

\begin{tabular}{|c|c|}
\hline \multicolumn{2}{|c|}{ Macro } \\
\hline Sector & Ergonomic best practices \\
\hline Organization or company & Ergonomic policy, audit \\
\hline Plant or workplace & Ergonomic change teams \\
\hline Line or department & $\begin{array}{l}\text { Tilted production line, } \\
\text { reorganized flow }\end{array}$ \\
\hline Work group & $\begin{array}{l}\text { Safety climate training, } \\
\text { job rotation }\end{array}$ \\
\hline Job & Job enlargement, regular brea \\
\hline Worker & $\begin{array}{l}\text { Ergonomic training, } \\
\text { workstation adjustment }\end{array}$ \\
\hline Task or tool & $\begin{array}{l}\text { Sharpening improvements, } \\
\text { new trimming tools, lift assist }\end{array}$ \\
\hline & \\
\hline
\end{tabular}

Figure 1. Levels of workplace intervention to reduce mechanical exposures and corresponding examples of each level. ("Worker" is recognized as somewhat distinct from the other levels but pertinent to intervention design and evaluation.)
Difficulties can be associated with the estimation of efficiencies (40), often requiring close workplace-researcher partnerships to generate valid and essential data (42) similar to the requirements for valid effectiveness evaluations.

\section{Levels of action}

A complicating factor when workplace intervention to reduce mechanical exposures is considered is that it can be aimed at multiple levels, from workplace policies and organizational design (macro) through work group training (meso) to the level of individual tasks (micro). (See figure 1.) Earlier reviews have catalogued studies aimed at making changes across the macro-micro spectrum, from organizational structures and employee relations to job design and task requirements $(3,11,13,15,25$, 43, 44).

We have found it helpful to think of ways in which change at each of the levels in figure 1 (organization or company, plant or workplace, line or department, work group, job, worker, and task or tool) can alter the amplitude, time variation pattern, or duration of physical risk factors at the job or worker level. In our work, requirements for workplace ergonomic audits by corporate management in a multinational manufacturing corporation catalyzed development of a better way of releasing foam from a mold and thus reduced the amplitude of peak spinal loads associated with demolding. Similarly, a hospital workplace policy requiring at least two persons to lift a patient has the potential to reduce the amplitude of spinal loads substantially. Engineering intervention involving the redesign of the trimming and packing process on a production line reduced the frequency of twisting and pulling tasks on that job. The sharing of jobs through job rotation within a work group or job enlargement altered the time variation of physical exposures. In other work, training in workstation adjustment resulted in improvements in the proportion of workers carrying out adequate adjustments (45). In meat-processing plants, training to improve task performance, such as knife sharpening, and the modification of tools, can both be expected to reduce the amplitude of forces (46).

Evaluations need to be designed according to the primary level of an intervention. For example, the redesign of an entire production system of a plant should be evaluated with the use of a pre-post design with another similar plant, preferably within the same company, as reference. An evaluation of work-group-based ergonomic change processes would benefit from a stratification of the groups by key characteristics and then staggered implementation evaluation designs. Selecting workers with musculoskeletal problems for the random allocation of the timing of specific interventions (eg, 
exercises, workstation adjustments) is appropriate for the evaluation of secondary prevention initiatives (47).

We suggest that, rather than make blanket statements about the evaluability of "ergonomic interventions", the level of intervention be considered explicitly. Many interventions are applied as programs, to maximize change efforts $(32,40)$. Increasingly, multifaceted intervention is advocated (including engineering, behavioral, and administrative changes) at multiple levels within the organization, in keeping with macro- as well as micro-ergonomic approaches $(48,49)$. Some have argued that such an approach is the preferred way of implementing ergonomic programs (3) even though they pose challenges to the documentation and evaluation of changes at each level.

\section{Indicators of conditions, interventions and outcomes}

In order to link interventions to reductions in mechanical exposure and then on to meaningful outcomes for workplace parties, we see the need for multiple indicators along a path connecting plausible steps or nodes. (See figure 2.) The model builds on earlier models (50, $51,12)$ that link constructs in a cascade fashion from broader determinants at organizational levels (nodes 12) through targeted impacts at more micro-levels (nodes 3-4), mechanical exposure in particular, and back to broader organizational outcomes (nodes 5-7) (nodes identified in figure 2).

Nodes 1, 2, and 3. Of interest here are workplace attitudes and practices (node 1), which lead to changes in

\section{Conditions and modifiers}

Resources
Commitment to change
Management competence

Adequate resources (personnel, monetary resources) Ergonomic competence Adherence or coverage

Time delay

Distribution of WMSD symptoms Work organization

Workplace and work organization Reporting policies and procedures Psychological factors

Psychosocial supports Therapeutic maintenance at work On-site physiotherapy, education Reactive workplace changes

Psychosocial supports Therapeutic return to work Clinical treatment
Nodes in path

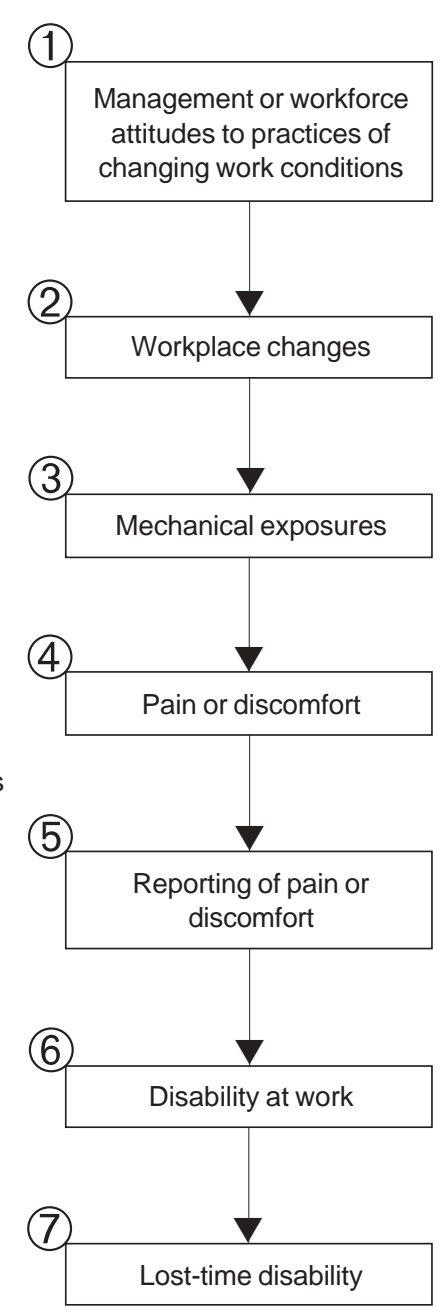

\section{Indicators}

LEADING

Health and safety emphasis in corporate management or labor relations

Magnitude, number and rate of changes

Individual and system level exposure via self-report, observation, technical measure, or posture, force (moment), frequency and duration

Self-report pain and discomfort symptoms on survey or active surveillance

First aid

Medical visits

No lost-time workers' compensation claims

Disability of the arm, shoulder or hand Work limitations

Productivity or quality reductions

Lost-time workers' compensation Sickness absence and associated costs Indirect cost including replacement, retraining

LAGGING

Figure 2. Nodes in the path through which changes in mechanical exposures can be effected and have beneficial impacts on work-related musculoskeletal disorders (WMSD). 
work organization, job design, equipment, layouts, and the like (node 2), which, in turn, may reduce measurable mechanical exposures (node 3 ). Considerable observational evidence exists for the important role of the first (52). Nevertheless, evaluations of intentional redesigns have had less success in demonstrating impacts of workplace changes (node 2) on mechanical exposures (node 3).

In Westgaard \& Winkel's (11) review of ergonomic interventions, of the 20 studies addressing mechanical exposure, only about one quarter evaluated the effect of the intervention on exposure. Among the studies using production system intervention or rationalization strategies, less than half evaluated the effect of the intervention on exposure. As an example, Aborg et al (53) found that work reorganization at the departmental level among Swedish office workers resulted in essentially no change in mechanical exposures as measured by surface electromyography and other means. Translating knowledge into effective actions is also a challenge that may be related to both resources and practical competencies. For example, Daltroy et al (54) showed that, although a "back school" improved knowledge, there was no observable improvement in work methods, the proxy for exposure.

Among the conditions modifying linkages between nodes are the extent of adherence by members of the workplace and the intensity of the intervention, often framed as threats to validity in quasi-experimental designs. For example, feedback from supervisors and workers on the use of recently introduced powered lifting assists in a stamping operation indicated that many people in the department were not familiar with the use of the lift assists and that breakdowns resulted in the lift assists not being available much of the time (14). Challenges in assessing intensity include issues of adherence, coverage (eg, how many workers have adequately designed ergonomic tools available), and metrics. For example, for a platform designed to reduce low back loading by angling and elevating product bins off the floor, what is the appropriate metric for load reduction: peak load (in Newtons), amount of time (in seconds or percent) less than a reference threshold (eg, 3400 N, NIOSH lifting guidelines) or cumulative load? Furthermore, should load reduction be assessed as if only one person does the task, weighted for the proportion of time at a workstation (given job rotation), or aggregated across the work group? Task-based measures may be more specific, but work-group-based measures may be more relevant to organizational outcomes (nodes 5 to 7 ).

Nodes 3 and 4. Linking reduced pain or discomfort (node 4) to reduced mechanical exposure (node 4) is crucial for delineating the effects of exposure reductions from other effects that interventions may have, as per Volin's critique (12). A good example of making a plausible link is provided by Aarås (55), whose workstation changes reduced both measured physical exposures and shoulder symptoms among computer-assisted design operators. On the other hand, Demure et al (56) found a reduction in discomfort after ergonomic intervention but the reduction had little relationship to the extent of improvement. Marras and his colleagues (7) prospectively followed the impacts of workplace changes to address low-back pain. They observed that only some changes were effective in reducing exposure (using, for example, lifting aids) and hence subsequent injury reports.

Nodes 4, 5, and 6. Rates of incident reports, first aid, or first-time occupational visits are often the organizational outcomes most sensitive to the impact of ergonomic intervention (57). Unfortunately, in our experience, there is considerable variation in the threshold for reporting, the manner of data collection, the way incidents are classified, and the systems for collecting, aggregating and sharing incident reports. Linkage between levels of pain or discomfort (node 4) in a working population and reports to the workplace (nodes 5 and 6) may be loose $(58,59)$, as demonstrated by the "iceberg" of burden measures observable in a newspaper worker population, in which only about one-third of those with pain during the last year reported it to the workplace. Reporting practices may improve as a result of intervention, the result being paradoxical (60). Furthermore, at a given level of pain or discomfort (node 4), people may experience different problems with function (node 6), as measured by a health-related quality-of-life instrument such as the Disability of the Arm, Shoulder and Hand (61), and varying ability to carry out job tasks, as measured by an instrument such as the Work Limitations/ Role Function Questionnaire (62). Webb and his colleagues (63) provide a useful filter model for understanding variation in injury reports across different levels in the workplace and in broader company administration. Because of such filters, joint measurement of pain or discomfort and function at the individual level and the recording of reporting rates at the departmental or workplace level need to become more standard practice in evaluation studies.

Nodes 6 and 7. The extent to which problems carrying out job tasks (node 6) are linked with absence from work (node 7) depends in large measure upon workplace disability management practices, including the provision of modified work (64). Variation in benefit levels, administrative procedures, and guidance given employees may result in such lost time and show up either in workers' compensation or weekly indemnity or sickness absence rates. For this reason, some companies include 
both types of indicators in their routinely reported workplace health and safety data (Reeves G, personal communication). Since wage replacement costs for absent employees are some of the major costs borne by workplaces, such data are crucial as organizational outcome, although some caution must be observed because of the relative rarity of lost-time events, the variable time required for intervention to have an effect on more serious outcomes, and the problems of carryover of assigned liabilities across years. For example, Norman \& Wells (14) cite the example of an injury occurring in the year prior to the introduction of lifting assists in a manufacturing plant having a persistent and major impact on costs to the company.

An encouraging movement is to bring indicators across the nodes together within a scorecard of leading and lagging indicators (65). Leading indicators refer to the more upstream nature of programs and activities and lagging indicators belong to the more downstream nature of human health outcomes, with job conditions, such as mechanical exposure, in the middle. Unfortunately, few workplaces are currently tracking the full suite of appropriate measures relevant to nodes along the path, and therefore it is left to intervention researchers to invest resources in measuring missing indicators and to bring together such indicators into a coherent picture for workplace parties.

\section{Application}

So how might researchers draw on their understanding of cultures of evidence, levels of intervention, and indicators along causal paths to better evaluate workplace interventions to reduce mechanical exposures? Depending on the intervention of primary interest, the willingness of workplace parties to participate in such evaluations, and the resources available, one could imagine a diverse range of approaches employing multiple observational methods, across different levels, with multiple indicators. An area of active interest for us has been participatory ergonomic change processes of work and equipment redesign in collaboration with workplace parties.

In our research, ergonomic change teams, made up of workplace parties and researcher facilitators, go through a process of problem identification, problem characterization, solution building, and solution evaluation in an iterative fashion using a "blueprint model that draws from a variety of disciplines and parallels quality management approaches (66). Although primarily a meso-level strategy, ergonomic change teams aim at bringing about changes in the way ergonomics are incorporated into plant- or organization-wide decision making (macro level), as well as in concrete changes in work design (meso level) and equipment and tools (micro level). We have found qualitative methods of data collection (participatory observation, field notes, and interviews) and analysis (theme identification, thick description, linkage with theory) to be invaluable in better understanding the "how" of participatory ergonomic change (nodes 1 and 2) $(67,68)$.

To document the variety of concrete changes undertaken (eg, 27 changes on one line in one plant), we developed complementary methods to describe the equipment, task, or tool changes made (eg, an ergonomic change documentation form, node 2), perceptions of the changes by employees (ie, a 1-minute survey, node 3 ), and measurement of changes that occur in biomechanical exposure (node 3). The last includes detailed observational checklists (eg, Manufacturing Operations Risk Factor) and software adaptions of laboratory-based measurement tools for more intensive measurement [eg, 4D Watbak, available at www.escs.uwaterloo.ca). The latter includes task breakdowns (aided where available by industrial engineering studies) to account for all significant loads and postures during a shift. Forces exerted on the body, as well as pinch and grip forces, are measured using appropriate force transducers. These forces, as well as postures obtained from video, are entered into biomechanical modeling and assessment software (69). This software estimates peak and cumulative loading on the low back and shoulder and can be extended to cover the distal arm (70). As well, we use surface electromyography of the shoulders and forearms to provide information on task demands, and this information appears to parallel results from epidemiologic investigations (71). Such tools permit a detailed characterization of the nature of a particular change and precise quantification of its impact on biomechanical exposures (Frazer et al, unpublished results).

For direct employee data, we primarily use an intervention-specific survey. Constructs in the survey include broad perceptions of workplace health and safety culture and communication (node 1), complementary to the qualitative data on group processes; ratings of perceived physical exertion (node 3) (eg, force required, repetitions, extent to which work is tiring, which is complementary to the ergonomic change specific descriptions); more general job characteristics [eg, influence, control, security, which both provide information on other relevant risk factors for work-related musculoskeletal disorders using well-tested instruments $(8,10)]$; and pain or discomfort measures (node 4), including frequency, duration, intensity, and location, which, according to earlier work (72), demonstrate construct validity with respect to measures of function and disability. In particular, we have adapted the pain intensity measure developed by Von Korff and his colleagues (73) (pain over the last 7 days + average pain during the last 6 months + worst pain during the last 6 months) and have found 
it has superior psychometric performance as a continuous measure of severity when compared with other possible outcome measures for work-related musculoskeletal disorders (Smith et al, unpublished results).

Finally, at the plant or departmental level, we have obtained existing human resources and operations management data to assess changes in both injury- and health-related outcomes [eg, first aid, absenteeism (nodes 5-7)] and production outcomes (eg, right-firsttimes) meaningful to workplace parties $(74,75)$. We carry out this activity over three time periods, before researcher involvement, during the ergonomic intervention process and after major researcher involvement with the plant when ergonomic change teams continue working but in a less intense manner.

Such a suite of indicators of both change processes and outcomes at different levels and for different links along the path can be grouped into case studies for each experience (76). Within the case studies, qualitative findings can be compared with quantitative findings and comparisons made across the different kinds of quantitative data with the intent of "triangulation"or cross-validation (77). Such enriched case studies can add to the extensive existing case study literature on ergonomic intervention.

To enhance inference on the impact of ergonomic intervention, several additional design and analytical steps are being taken. First, we are seeking to characterize the nature and extent of ergonomic changes and the factors influencing both the changes made and the impacts occurring in order to compare and contrast experiences in a multiple case-study design (82). Second, we have staggered the timing of ergonomic intervention in paired departments, plants, or worksites and permitted the later intervention sites of the pairs to act as timebased referents in keeping with quasi-experimental approaches (26). For each of these two actions, the full range of indicators is appropriate. Third, by concentrating on similar-sized worksites and using the same person-based measures in each worksite, our aim is to pool person-based data across experiences to achieve sufficient sample size for quantitative inference testing. Depending on the homogeneity in observed variable distributions, this action can occur either directly or using meta-analytic approaches. Through each of these approaches, we look for convergence or divergence in impacts and the reasons for each.

Our approach, which includes many of the features of both methodologically rigorous and societally relevant intervention evaluation, should provide evidence for the effectiveness of meso-level workplace ergonomic intervention that speaks to the majority of cultures of evidence that we described earlier. It does not exclude the possibility of considering more rigorous designs in future work, such as randomized trials across a range of medium-sized workplaces, provided that key elements of effective intervention in appropriate contexts can be identified in our current work and those of others, institutional support can be gleaned from organizations of workplaces that provide an appropriate sampling frame, workplace parties in participating worksites can provide access to production, quality and injury data and agree to randomized time-lagged intervention with ongoing participation and monitoring tasks, sufficient similarity of the intervention process and comparability of the specific changes can be assured, ongoing cointervention can be documented and accounted for, and substantially greater amounts of research resources can be mobilized. Currently such a list is a tall order in most jurisdictions, but, as the pressure to produce better evidence increases, we can only hope that research responses can be similarly enriched in ways that are meaningful for workplace stakeholders, who make the fundamental decisions determining workplace biomechanical exposures (78).

\section{Acknowledgments}

We thank the workplace parties (companies, unions and employees) that we have worked with over the last 5 years and that have assisted us in understanding problems, testing responses, and building frameworks.

Financial support for our work has been provided by the National Centres of Excellence via the Health Evidence \& Application Linkage Network (HEALNet) and the Workplace Safety and Insurance Board through the Ontario Research Advisory Committee's Solutions for Workplace Change extramural grant program and directly to the Institute for Work \& Health.

\section{References}

1. Hagberg M, Silverstein B, Wells R, Smith R, Carayon P, Hendrick $\mathrm{H}$, et al, editors. Work-related musculoskeletal disorders (WMSD): a handbook for prevention. London: Taylor and Francis; 1995.

2. Bernard BP, editor. Musculoskeletal disorders and workplace factors. a critical review of epidemiologic evidence for workrelated musculoskeletal disorders of the neck, upper extremity and low back. Cincinnati (OH): National Institute for Occupational Safety and Health; 1997. DHHS (NIOSH) publication, no 97-141.

3. Panel on Musculoskeletal Disorders and the Workplace, Commission on Behavioral and Social Sciences and Education, National Research Council and Institute of Medicine. Musculoskeletal disorders and the workplace: low back and upper extremities. In: Interventions in the workplace.Washington (DC): National Academy Press; 2001. p 301-29.

4. Punnett L, Fine LD, Keyserling WM, Herrin GD, Chaffin DB. Back disorders and nonneutral trunk postures of automobile assembly workers. Scand J Work Environ Health 1991;17:337-346.

5. Punnett L, Bergqvist U. Visual display unit work and upper 
extremity musculoskeletal disorders: a review of epidemiological findings. Solna (Sweden): National Institute for Working Life, Ergonomic Expert Committee; 1997. Document no 1:16.

6. Marras WS, Lavender SA, Leurgans SE, Rajulu SL, Allread WG, Fathallah FA, et al. The role of dynamic three-dimensional trunk motion in occupational-related low back disorders: the effects of workplace factors trunk position and trunk motion characteristics on risk of injury. Spine 1993;18(5):61728.

7. Marras WS, Allread WG, Burr DL, Fathallah FA. Prospective validation of a low-back disorder risk model and assessment of ergonomic interventions associated with manual materials handling tasks. Ergonomics 2000;43(11):1866-86.

8. Norman R, Wells R, Neumann P, Frank J, Shannon H, Kerr M. A comparison of peak vs. cumulative physical work exposure risk factors for the reporting of low back pain in the automotive industry. Clin Biomech (Bristol, Avon) 1998;13:561-73.

9. Ariëns GAM, van Mechelen W, Bongers PM, Bouter LM, van der Wal G. Physical risk factors for neck pain [review]. Scand J Work Environ Health 2000;26(1):7-19.

10. Kerr MS, Frank JW, Shannon HS, Norman R, Wells R, Neumann P, et al. Biomechanical and psychosocial risk factors for low back pain at work. Am J Public Health 2001;91(7):1069-75.

11. Westgaard RH, Winkel J. Ergonomic intervention research for improved musculoskeletal health: a critical review. Int J Ind Ergon 1997;20:463-500

12. Volin E. Do workplace interventions prevent low-back disorders? If so, why?: a methodologic commentary. Ergonomics 1999;42(1):258-72.

13. Grant K, Habes D, Schneider S. Summary of studies on the effectiveness of ergonomic interventions. Appl Occup Environ Hyg 1995;10(6):523-30.

14. Norman R, Wells R. Ergonomic interventions for reducing musculoskeletal disorders. In: Sullivan T, editor. Injury and the New world of work. Vancouver (BC): UBC Press; 2000. p 115-139.

15. Kilbom $\AA$. Intervention programmes for work-related neck and upper limb disorders: strategies and evaluation. Ergonomics 1988;31(5):735-47.

16. Silverstein B. Evaluation of interventions for control of cumulative trauma disorders. In: American Congress of Governmental Industrial Hygienists, editors. Ergonomic interventions to prevent musculoskeletal injuries. Chelsea (MI): Lewis; 1987. p 87-99.

17. Cole DC, Stock SR, Gibson ES. Workplace based interventions to reduce overuse disorders of the neck and upper extremity: an epidemiologic review. In: Proceedings of the 25th Annual Conference of the Human Factors Association of Canada. Hamilton, Ontario: Human Factors Association of Canada; 1992. p 263-9.

18. Buckle P. Musculoskeletal injuries and their prevention: assessment of interventions. In: Seppälä P, Luopajärvi T, Nygard C-H. Proceedings of the 13th Triennial Congress of the International Ergonomics Association, June 29-July 4, 1997: vol 4. (Musculoskeletal disorders \& rehabilitation). Tampere (Finland): Finnish Institute of Occupational Health. p 141145.

19. Douglas M, Wildavsky A. Risk and culture. Berkeley and Los Angeles (CA): University of California Press; 1982.

20. Gunning J, Callaghan J, McGill SM. The role of prior loading history and spinal posture on compressive tolerance and type of failure in the spine using a porcine trauma model. Clin
Biomech (Bristol, Avon) 2001;16(6):471-80.

21. Keir PJ, Wells R, Ranney D, Lavery W. The effects of tendon load and posture on carpal tunnel pressure. J Hand Surg 1997;22(4):628-34.

22. Daynard D, Yassi A, Cooper J, Tate R, Norman R, Wells R. Biomechanical analysis of peak and cumulative spinal loads during simulated patient handling: a sub-study of a randomized controlled trial of measures to prevent lift and transfer injury to health care workers. Appl Ergon 2001;32:199214.

23. Malmivaara A. Evidence-based intervention for musculoskeletal disorders. Scand J Work Environ Health 1997;23:161-3.

24. Rivara FP, Thompson DC. Systematic reviews of injuryprevention strategies for occupational injuries: an overview. Am J Prev Med 2000;18(4):1-3.

25. Zwerling C, Daltroy L, Fine L, Johnson J, Melius J, Silverstein B. Design and conduct of injury intervention studies: review of evaluation strategies. Am J Ind Med 1997;32:16479.

26. Robson LS, Shannon HS, Goldenhar LM, Hale AR. Guide to evaluating the effectiveness of strategies for preventing work injuries: how to show whether a safety intervention really works. Cincinatti $(\mathrm{OH})$ : National Institute of Occupational Safety and Health; 2001. p 121. DHHS(NIOSH) publication, no 2001-119.

27. Ketola R, Toivonen R, Häkkänen M, Luukkonen R, Takala E$\mathrm{P}$, Viikari-Juntura E, et al. Effects of ergonomic intervention in work with video display units. Scand J Work Environ Health 2002;28:18-24.

28. Elden M, Taylor JC. Participatory research at work: an introduction. J Occup Behav 1983;4:1-8.

29. St Vincent M, Toulouse G, Bellemare M. Démarches d'ergonomie participative pour réduire les risques de troubles musculo-squelettiques: bilan et réflexions [The process of participatory ergonomic interventions to reduce the risks for musculoskeletal disorders: evaluation and reflection]. Pistes [serial online] 2000; 2(1):1-38. Available from URL: www.unites.uqam.ca/pistes/v2n1/articles/v2n1a5.htm

30. Westlander G. Means, goals and outcomes of a comprehensive occupational health program for telephone operators. Int J Health Serv 1995;25(2):313-32.

31. Griffiths A. Organizational interventions: facing the limits of the natural science paradigm. Scan J Work Environ Health 1999;25(6, special issue):589-96.

32. Cole DC, Wells RP. Interventions for musculoskeletal disorders in computer intense office work: a framework for evaluation. Work Stress 2002;16(2):95-106.

33. Frank JW, Lomax G. Public health action to control hazards: how good should the evidence be? Reflections on the OSHA Ergonomics Standard hearings. New Solutions 2002;12(1):1725.

34. Huberman M, Miles MB. Innovation up close: how school improvement works. New York (NY): Plenum Press; 1984.

35. Mintzberg H, Westley F. Cycles of organizational change. Strategic Manage J 1992;13:39-59.

36. Needleman C, Needleman ML. Qualitative methods for intervention research. Am J Ind Med 1996;29:329-37.

37. Mergler D. Combining quantitative and qualitative approaches in occupational health for a better understanding of the impact of work-related disorders. Scand J Work Environ Health 1999;25 Suppl 4:54-60.

38. Badham R, Couchman P, Little S. Getting smart: developing an action research approach to the integrated management of technical and organizational innovation. Hum Syst Manage 
1995;14:91-104

39. Oxenburgh MS. Increasing productivity and profit through health and safety. Sydney: CCH International; 1991.

40. United States (US) Government Accounting Office. Report to congressional requesters on worker protection: private sector ergonomics programs yield positive results. Washington (DC): US Government Accounting Office; 1997. GAO/ HEHS 97-163.

41. Neumann WP, Kihlberg S, Medbo P, Mathiassen SE, Winkel J. A case study evaluating the ergonomic and productivity impacts of partial automation strategies in the electronics industry. Int J Prod Res 2002;40(16):4059-75.

42. Lanoie P, Tavenas S. Costs and benefits of preventing workplace accidents: the case of participatory ergonomics. Saf Sci 1996;24(3):181-96.

43. Goldenhar LM, Schulte PA. Intervention research in occupational health and safety. J Occup Med 1994;36:763-75.

44. Lincoln AE, Vernick JS, Ogaitis S, Smith GS, Mitchell CS, Agnew J. Interventions for the primary prevention of workrelated carpal tunnel syndrome. Am J Prev Med 2000;18(4):37-50.

45. Montreuil S, Brisson C, Arial M, Trudel L. Évaluation des effets d'un programme de formation chez les utilisateurs de terminaux à écran de visualisation. Montréal: Institut de recherche en santé et en sécurité du travail; 1997.

46. May DR, Schwoerer CE. Employee health by design: using employee involvement teams in ergonomic job redesign. Pers Psychol 1994;47:861-76.

47. Mekhora K. Effect of computer workstation set-up on tensions neck syndrome [dissertation]. Curtin (New Zealand): Curtin University of Technology; 1999.

48. Hendrick HW. Macro ergonomics as a preventative strategy in occupational health: an organizational level approach In: Bradley GE, Hendrick HW, editors. Human factors in organizational design and management IV. North-Holland: Elsevier Science BV; 1994.

49. Baker E, Israel BA, Schurman S. The integrated model: implications for worksite health promotion and occupational health and safety practice. Health Educ Q 1996;23:175-90.

50. Armstrong TJ, Buckle P, Fine LJ, Hagberg M, Jonsson B, Kilbom A, et al. A conceptual model for work-related neck and upper-limb musculoskeletal disorders. Scand J Work Environ Health 1993;19:73-84.

51. Sauter SL, Swanson NG. An ecological model of musculoskeletal disorders in office work. In: Moon SD, Sauter SL, editors. Beyond Biomechanics: psychosocial aspects of musculoskeletal disorders in office work. London: Taylor \& Francis; 1996. p 3-22.

52. Shannon HS, Mayr J, Haines T. Overview of the relationship between organizational and workplace factors and injury rates. Saf Sci 1997;26:201-17.

53. Aborg C, Fernstrom E, Ericson MO. Work content and satisfaction before and after a reorganization of data entry work. Appl Ergon 1998;29(6):473-80.

54. Daltroy I, Iversen M, Larson M, Ryan J, Zwerling C, Fossel A, et al. Teaching and support: effects on knowledge, attitudes and behaviours to prevent low back injuries in industry. Health Educ Q 1993;20:3-62.

55. Aarås, A. Relationship between trapezius load and the incidence of musculoskeletal illness in the neck and shoulder. Int J Ind Ergon 1994;14:341-8.

56. Demure B, Mundt KA, Bigelow C, Luippold RS, Ali D, Liese B. Video display terminal workstation improvement program, II: ergonomic intervention and reduction of musculoskeletal discomfort. J Occup Environ Med 2000;42(8):792-7.

57. McKenzie F, Stormeni J, Van Hook P, Armstrong TJ. A program for control of repetitive trauma disorders associated with hand tool operations in a telecommunications facility. Am Ind Hyg Assoc J 1988;46(11):674-8.

58. Chung J, Cole DC, Clarke J. Women, work and injury. In: Sullivan T, editor. Injury and the new world of work. Vancouver: University of British Columbia Press; 2000. p 60-90.

59. Hogg-Johnson S, Cole DC, Côté P, Frank J. Staging treatment interventions following soft-tissue injuries. In: Sullivan $\mathrm{T}$, editor. Injury and the new world of work. Vancouver: University of British Columbia Press; 2000. p 201-18.

60. British Standards Institute. Guide to occupational health and safety management systems. London: British Standards Institute; 1996. ICS 13.100, BS 8800.

61. Hudak PL, Amadio PC, Bombardier C, the Upper Extremity Collaborative Group. Development of an upper extremity outcome measure: the DASH (Disabilities of the Arm, Shoulder and Hand). Am J Ind Med 1996;29:602-8.

62. Lerner D, Amick BC, Rogers WH, Malspeis S, Bungay K, Cynn D. The work limitations questionnaire. Med Care 39;1:72-85.

63. Webb GR, Redman S, Wilkinson C, Sanson-Fisher RW. Filtering effects in reporting work injuries. Accid Anal Prev 1989;21:115-23.

64. Brooker A-S, Cole DC, Hogg-Johnson S, Smith J, Frank JW, the Early Claimant Cohort Prognostic Modeling Group. Modified work: prevalence and characteristics in a sample of workers with soft tissue injuries. J Occup Envirion Med 2001;43(3):276-84.

65. Robson LS, Severin C, Cole DC, Hepburn G. Institute for Work \& Health-St Michael's Hospital collaborative development of a healthy workplace balanced scorecard: identification of SMH priorities in employee health and safety and potential indicators. Interim Report and Discussion Paper, 2001.

66. Wells R, Norman R, Frazer M, Laing A. Ergonomics program implementation blueprint, ergonomics and safety consulting services, Waterloo: University of Waterloo; 2001.

67. Theberge N, Granzow K, Greco L, Neumann P, Cole D, Brawley L, et al. Participatory Ergonomics: assessing the impact of different forms of involvement on reported outcomes. Paper presented at the annual scientific meeting of the Association of Canadian Ergonomists, Quebec, Montreal; 2001

68. Theberge N, Granzow K, Cole DC, Laing A, Ergonomic Intervention Evaluation Group. Negotiating participation: understanding the "how" in a workplace ergonomic change program. Toronto: Institute for Work \& Health; 2003. IWH working paper, no 220.

69. Neumann P, Wells R, Norman R. 4D- WATBAK: adapting research tools and epidemiologic findings to software for easy application by industrial personnel. In: Proceedings of the International Conference on Computer-Aided Ergonomics and Safety, Barcelona, Spain. 1999.

70. Wells R, Norman R, Neumann P, Andrews D, Frank J, Shannon $\mathrm{H}$, et al. Assessment of physical work load in epidemiologic studies: common measurement metrics for exposure assessment. Ergonomics 1997;40:51-61.

71. Wells R, Shannon H, Cole D, Norman R. Electromyographic protocols for measurement of exposure in VDT operators. Johns Hopkins University; 1998. Final report for the Center for VDT and Health Research.

72. Beaton DE, Cole DC, Manno M, Bombardier C, Hogg-Johnson S, Shannon HS. Describing the burden of upper extremity 
musculoskeletal disorders in newspaper workers: what difference do case definitions make? J Occup Rehabil 2000;10(1):39-53.

73. Von Korff M, Dworkin SF, Le Resche L. Graded chronic pain status: an epidemiologic evaluation. Pain 1990;40:27991.

74. Pransky G, Himmelstein J. Outcomes research: implications for occupational health. Am J Ind Med 1996;29:573-83.

75. Häkkänen M, Viikari-Juntura E, Martikainen R. Incidence of musculoskeletal disorders among newly employed manufacturing workers. Scand J Work Environ Health 2001;27(6):3817.

76. Yin RK. Case study research: design and methods. Beverly
Hills (CA): Sage; 1984.

77. Mullen PD, Iverson DC. Qualitative methods. In: Green LW, Lewis FM. Measurement and evaluation in health education and health promotion. Palo Alto (CA): Mayfield Publishing Co; 1986. p 149-70.

78. Polanyi MF, Cole DC. Towards research-informed multistakeholder action oncomplex workplace health issues: reflections on two WMSD interventions. In: Sullivan T, Frank J, editors. Preventing work-related disability: new views. London: Taylor \& Francis; 2003. p 121-41.

Received publication: 16 June 2003 